\title{
AVALIAÇÃO DA SITUAÇÃO-PROBLEMA POR TUTORES E DISCENTES EM UM CURSO DE GRADUAÇÃO VIVENCIADO EM METODOLOGIAS ATIVAS
}

\author{
Rodrigo DORNELAS ${ }^{1}$ \\ Kelly da SILVA ${ }^{2}$ \\ Carla Patrícia Hernandez Alves Ribeiro CÉSAR ${ }^{3}$ \\ Aline Cabral de OLIVEIRA-BARRETO ${ }^{4}$ \\ Raphaela Barroso GUEDES-GRANZOTTI ${ }^{5}$
}

RESUMO: O objetivo do artigo é comparar as avaliações de discentes e tutores sobre os problemas utilizados em um curso de Fonoaudiologia estruturado em metodologias ativas. Para tanto foi analisada a avaliação formativa realizada por 30 discentes e quatro tutores do II Ciclo do curso de Fonoaudiologia de uma Universidade Pública. Foram analisadas as avaliações de 36 situações-problema por meio de escalas de zero (insuficiente) a quatro (ótimo), atribuídas para avaliar as situações-problema. Os resultados foram analisados estatisticamente (coeficiente Kappa e Mann-Whitney, com nível de significância de 5\%). Não houve concordância entre as avaliações dos problemas pelos alunos e pelos tutores (índice Kappa $=0,0036$ ), sendo que os discentes pontuaram as questões dos problemas com maiores notas (média: 3,7) quando comparadas aos dos tutores (média: 3,16), embora todos tenham atribuído, em média, boa facilidade para a resolução das situações-problema. Assim, não houve concordância entre as avaliações das situações problemas entre tutores e discentes.

PALAVRAS-CHAVE: Avaliação educacional. Ensino. Aprendizagem baseada em problemas.

\section{INTRODUÇÃO}

A necessidade de indivíduos com competências éticas, políticas e técnicas e, dotados de conhecimento, raciocínio, crítica, responsabilidade e sensibilidade para as questões da vida e da sociedade, capacitados para intervirem em contextos de incertezas e complexidades, fez com que as Instituições de Ensino Superior buscassem alternativas para a formação de profissionais da saúde. Dentro deste contexto, as metodologias ativas surgiram com uma possibilidade por trabalharem intencionalmente com problemas para o desenvolvimento dos processos de ensino-aprendizagem, valorizando o "aprender a aprender" em que a estratégia de ensino é centrada no discente (FREIRE, 2006; FERNANDES, 2008; GOMES et al., 2010).

${ }^{1}$ UFS - Universidade Federal de Sergipe. Lagarto - SE - Brasil. 49100-000 - rodrigodornela@uol.com.br 2 UFS - Universidade Federal de Sergipe. Lagarto - SE - Brasil. 49100-000 kelly_fonousp@yahoo.com.br

${ }^{3}$ UFS - Universidade Federal de Sergipe. Lagarto - SE - Brasil. 49100-000 - carlacesar@globo.com

4 UFS - Universidade Federal de Sergipe. Lagarto - SE - Brasil. 49100-000 alinecabralbarreto@gmail.com

${ }^{5}$ UFS - Universidade Federal de Sergipe. Lagarto - SE - Brasil. 49100-000 - raphaelabgg@ gmail.com 
No contexto de um módulo temático, utilizam-se problemas escritos para motivar o aluno a resgatar conhecimentos arquivados na memória, instigar dúvidas científicas, integrar conhecimentos e dirigir o estudo. O problema deve ser escrito para atingir objetivos educacionais determinados e os alunos deverão ser estimulados a estudar conteúdos pertinentes a esses objetivos, através da discussão do problema durante o tutorial e apresentar esses resultados em sessão posterior (LIMA; LINHARES, 2008).

As reflexões e discussões sobre as situações-problema (SPs), a que são expostos os discentes, são desencadeadoras da busca de fatores explicativos e a suposição de soluções para o problema. Desta forma, problematizar significa ser capaz de responder ao conflito intrínseco que um problema traz. Os conteúdos são construídos pelo discente que precisa reorganizar o material, adaptando-o à sua estrutura cognitiva prévia, para descobrir relações, leis ou conceitos que precisará assimilar; retirando da realidade elementos que conferem significado em direção à aprendizagem (GARCIA MADRUGA, 1996; ZANOTTO; DE ROSE, 2003; CYRINO; TORALLES-PEREIRA, 2004).

Para isso, alguns princípios devem ser seguidos na elaboração de um problema como: descrição neutra de um acontecimento ou conjunto de fenômenos que necessitam de explicação em termos de processo subjacente, princípios ou mecanismos; conduzir a uma atividade de resolução de problemas pelos estudantes; serem formulados de uma situação tão concreta quanto possível; ter um grau de complexidade adaptado ao conhecimento prévio de cada estudante (SCHMIDT, 1999; HITCHCOCK, 1997).

No enfrentamento das situações Problemas (SPs), os discentes que participam de metodologias ativas de aprendizagem implicam-se ativamente no mundo e, ao vivenciarem as tensões, passam a reconhecer as diferenças de práticas, demandas de produção do cuidado no cotidiano das redes de Saúde e desenvolvem a capacidade de transformar os impasses, as impossibilidades, em trabalhos e ações possíveis; tornando a reflexão uma prática cotidiana do processo de aprendizagem (KOLKHORST; YAZEDJIAN, 2007; KOH et al., 2008).

Dentro deste processo dinâmico de aprendizagem, a avaliação não pode ser estanque e sim processual, pode e deve ocorrer utilizando-se de múltiplas estratégias e em diferentes momentos do processo de aprendizagem, sendo o foco deste artigo a avaliação formativa, que ocorre ao longo do processo de aprendizagem e seu objetivo é 
a correção de falhas do processo educacional e a prescrição de medidas alternativas de recuperação das falhas de aprendizagem (BLOOM; HASTINGS; MADAUS, 1971).

Dentre as possibilidades de avaliação formativa, podem ser citadas a autoavaliação (realizada pelo aluno sobre o seu próprio desempenho); a avaliação interpares (realizada pelos membros de um grupo sobre o desempenho de cada um dos participantes) e a avaliação pelo professor/tutor realizada por escrito, em ficha própria. O tutor a preenche para identificar as atitudes, comportamentos e habilidades dos discentes e para avaliar o progresso de cada um diariamente. O discente avalia o tutor e as situações-problema (SILVA; SCAPIN, 2011).

Dentro desta visão de formação, em que o aluno deixa o papel de receptor passivo e assume o de agente principal responsável pela sua aprendizagem, docentes e discentes envolvem-se de forma diferente com o saber. Possibilita que o tutor redirecione responsabilidades e ofereça espaço para o desenvolvimento da autonomia do aluno, tornando-o capaz de gerenciar a sua formação. Este propósito está diretamente relacionado com a capacidade de dar e receber críticas, que na problematização é trabalhado fortemente durante a avaliação da participação no processo de maneira formativa. As avaliações na ABP se tornam um momento rico de conhecimento sobre si e sobre o outro (CHUEIRI, 2008; MARIN et al., 2010).

Como visto, o processo de avaliação em um curso de graduação em metodologias ativas tem papel de extrema importância na formação do profissional, assim como a SP apresenta-se como disparadora do conhecimento. Sendo assim, o objetivo deste trabalho é verificar se há concordância entre as avaliações dos discentes e tutores sobre os problemas utilizados em um curso de graduação em Fonoaudiologia.

\section{MÉTODO}

Este estudo, de caráter transversal, com análise quali-quantitativa dos dados integra o processo de avaliação do primeiro curso de Fonoaudiologia em Aprendizagem Baseada em Problemas do Brasil, implantado na Universidade Federal de Sergipe/UFS, Campus Antônio Garcia Filho. Foi aprovado pelo Comitê de Ética em Pesquisa da Universidade onde foram coletados os dados, sob o número de parecer 298.515/2013.

A população desta pesquisa é formada pelos discentes do II Ciclo do curso de Fonoaudiologia da UFS - Campus Antônio Garcia Filho e por docentes responsáveis pelas sessões de tutorial deste Ciclo. Foram excluídos os discentes desistentes do ciclo ou com faltas superiores a $25 \%$ da carga horária total do Ciclo. Tais critérios foram 
aplicados pelo fato de que os discentes do II ciclo estarem em contato com as disciplinas específicas da Fonoaudiologia. Assim, fazem parte do escopo deste estudo 30 discentes e quatro tutores.

Para coleta de dados, foi utilizada a Ficha que trata sobre a Avaliação do Problema pelo discente e pelo tutor, a qual solicita o preenchimento de dados como identificação da turma e do sujeito: discente ou tutor, data, nome e número do problema. Constam-se ainda 12 questões com legendas, em que A indica que a questão deve ser preenchida pelo aluno e $\mathrm{T}$ pelo tutor, sendo que, em sua maioria as questões são preenchidas por A e T, as quais foram selecionadas neste estudo.

Os assuntos abordados pelas questões selecionadas são: 1. Grau de facilidade para identificar as questões do problema; 2. Grau de facilidade para levantar hipóteses; 3. Grau de facilidade para estabelecer os objetivos do estudo; 4. Grau de facilidade para resolver o problema; 5. Grau de estimulação da discussão em grupo e 6. grau de abordagem das questões biopsicossociais. Para o preenchimento da ficha, é utilizada uma legenda em que: zero, significa insuficiente; um, significa fraco; dois, médio; três, bom e quatro, ótimo. Rotineiramente, esta ficha é preenchida, obrigatoriamente, ao final de toda Sessão Tutorial, por todos os envolvidos.

As notas atribuídas por tutores e discentes foram posteriormente tabulados no software de planilha eletrônica Excel (pacote Microsoft $®$ Office) para análise descritiva de dados e assim foram processados pelo SPSS ${ }^{\circ} 15.0$ para o Windows e o software estatístico livre R 2.11.1 para o Windows.

Foi utilizado o coeficiente Kappa para verificação de concordância interavaliadores (alunos e tutores). Os Índices de Kappa superiores a 0,75 indicam alta concordância inter-avaliadores, enquanto que valores entre 0,4 e 0,75 sugerem concordância intermediária e valores menores que 0,40 mostram baixa concordância (FLEISS, 1981). Ainda as notas atribuídas pelos tutores e discentes foram comparadas por meio do teste de Mann-Whitney, foi considerado grau de significância de $5 \%$ (p valor $<0,05)$.

\section{RESULTADOS}

Ao analisar as notas impostas às situações problemas, observaram-se que os alunos atribuíram maiores valores médios quando comparados aos tutores (Gráfico 1). Não houve concordância entre as avaliações dos problemas pelos alunos e pelos tutores, 
analisando-se todas as questões, de todos os problemas, com valor de índice KappaFleiss igual a 0,0036 .

Gráfico 1- Médias das notas atribuídas aos problemas pelos alunos e pelos tutores

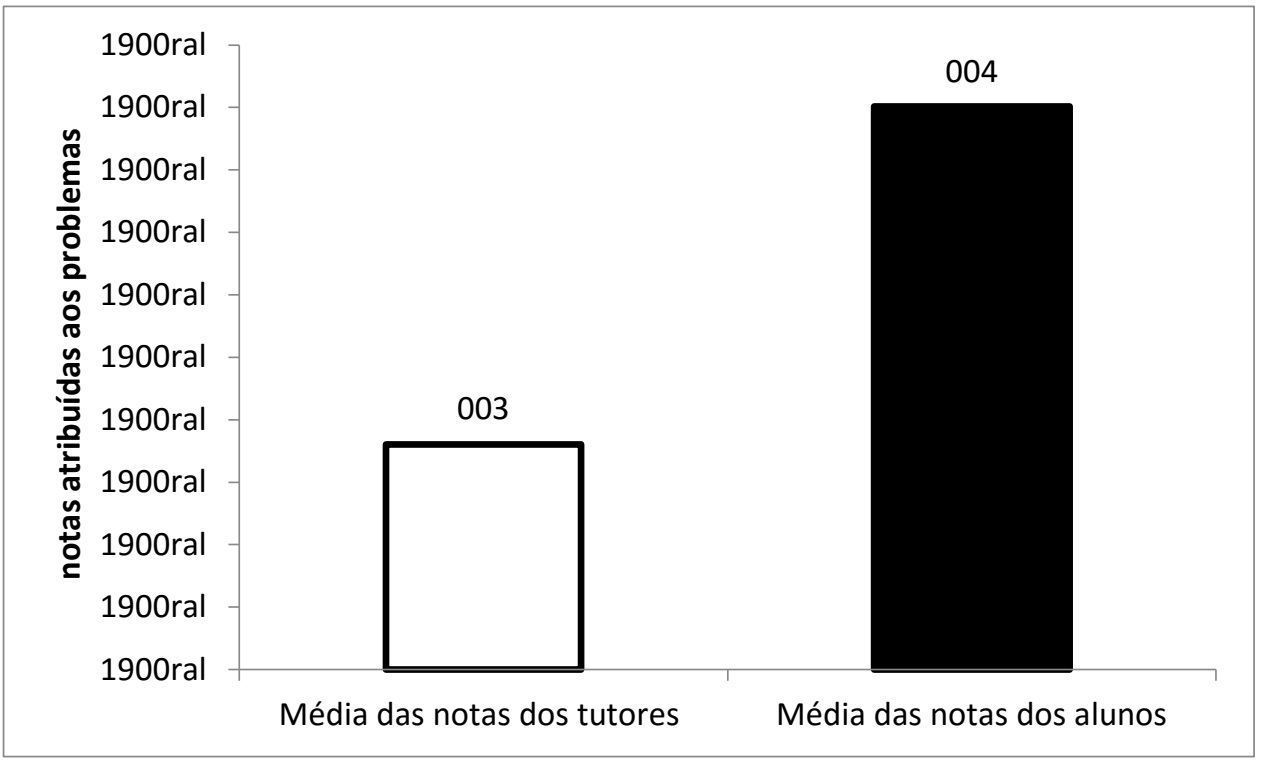

Fonte: Dados da pesquisa.

Foi observado também que as maiores discrepâncias entre as notas dos avaliadores foram, em ordem decrescente, nas seguintes questões: questão 4- grau de facilidade para resolver o problema, 6- abordagem biopsicossocial, 1- grau de facilidade de identificar às questões do problema, 3-facilidade para estabelecer os objetivos do estudo, 2- grau de facilidade para levantar hipóteses e 5- grau de estimulação da discussão em grupo (Gráfico 2). 
Figura 2- Média das notas atribuídas às questões de cada problema pelos tutores (barras claras) e pelos alunos (barras escuras).

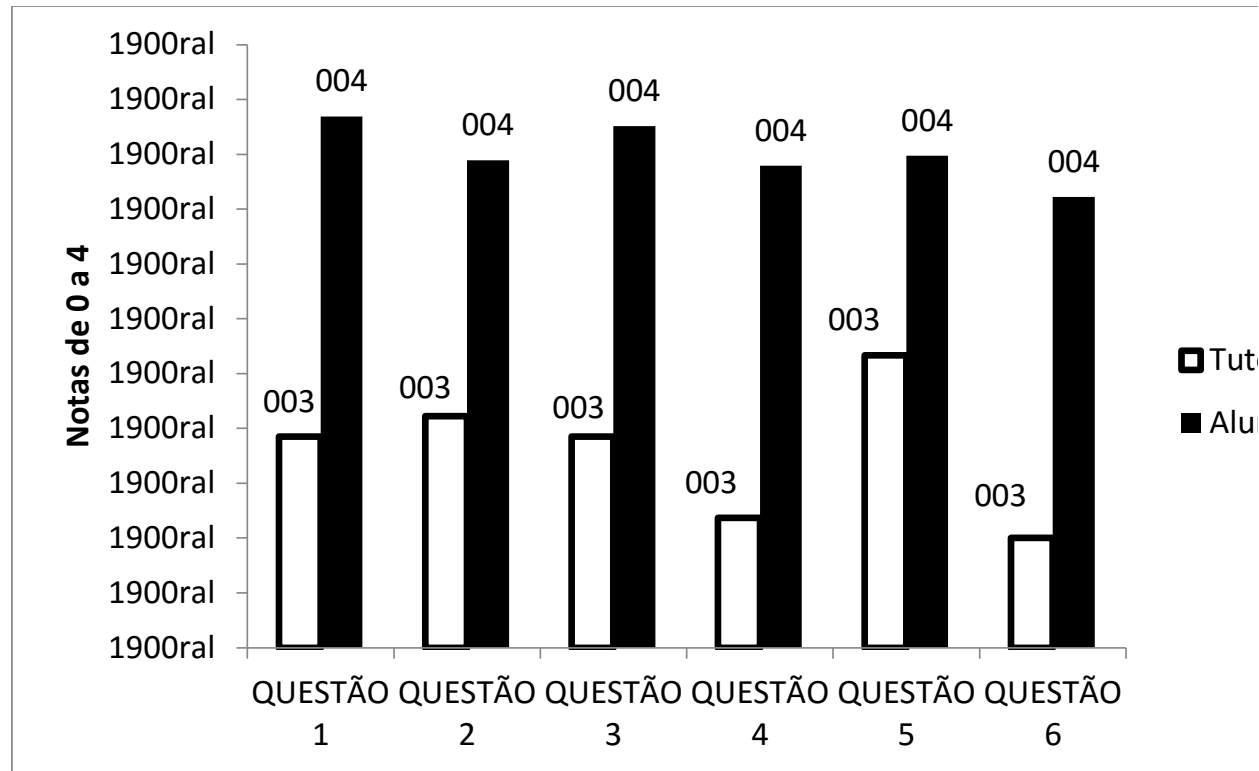

Legenda: Questão 1: Grau de facilidade para identificar as questões do problema; questão 2: grau de facilidade para levantar hipóteses; questão 3: grau de facilidade para estabelecer os objetivos do estudo; questão 4: Grau de facilidade para resolver o problema; questão 5: Grau de estimulação da discussão em grupo e questão 6: grau de abordagem das questões bio-psicosocial. As notas atribuídas às questões variaram de 0 a 4 , seno $0=$ insuficiente; 1= fraco; $2=$ médio; $3=$ bom e $4=$ ótimo.

Fonte: Dados da pesquisa.

Ao se comparar as notas atribuídas pelos tutores com as dos alunos, por meio do teste Mann-Whitney, foi identificada diferença significativa entre elas em todas as situações problemas (com $\mathrm{p}<0,001$ para a questão 1: grau de facilidade para identificar as questões do problema; questão 2: grau de facilidade para levantar hipóteses; questão 3: grau de facilidade para estabelecer os objetivos do estudo; questão 4: grau de facilidade para resolver o problema e questão 6: grau de abordagem das questões biopsicossocial e p<0,05 para a questão 5: grau de estimulação da discussão em grupo).

\section{DISCUSSÃO}

Os problemas são a força motriz no processo de $\mathrm{ABP}$ e são utilizados para envolver os discentes ativamente no percurso de aprendizagem proposto (DOMANS et al., 2005) e devem ser elaborados a partir de objetivos educacionais pré-determinados (LIMA; LINHARES, 2008). Esta não é uma tarefa simples, caso o problema não seja elaborado a partir de alguns princípios, e, dessa forma, parte dos objetivos podem não ser alcançados. A literatura (SCHMIDT, 1999; HITCHCOCK; ANDERSON, 1997) 
recomenda que os problemas contenham uma descrição neutra e concreta de um acontecimento, para que possam conduzir a uma atividade de resolução; além de apresentar complexidade adaptada ao conhecimento prévio de cada estudante, que nem sempre é fácil de ser identificado.

Assim, a análise constante das situações-problema por parte dos tutores é uma tarefa fundamental na condução do processo de ensino-aprendizagem em metodologias ativas. Isto para que os discentes, ao se depararem com as SPs, possam apreender o conteúdo proposto, mas não passivamente e sim de forma crítica e, para tanto, os objetivos são discutidos em grupo, ratificando o exposto por autores (KOLKHORST; YAZEDJIAN, 2007; KOH et al., 2008) quando argumentam que na ABP há a reflexão da prática cotidiana do processo de aprendizagem.

Essa reflexão cotidiana sobre o processo de aprendizagem requer tanto do tutor quanto do discente, disponibilidade, interesse, motivação e identificação da importância do seu papel no momento em que avaliam cada SP, atividade esta desenvolvida a cada fechamento de sessão tutorial. A avaliação é uma tarefa constante na vida do professor, mas não faz parte da vida do discente. Ademais, há dificuldades, por parte do tutor, em adotar o processo de avaliação formativa, pois sua formação foi permeada por avaliações somativas. A avaliação formativa exige diferentes formas e estratégias de acompanhamento do rendimento acadêmico do discente, sendo que autores (BLOOM; HASTINGS; MADAUS, 1971) apontaram que seu objetivo é a correção de falhas do processo educacional e a prescrição de medidas alternativas de recuperação dessas falhas de aprendizagem.

Esta é, portanto, uma tarefa que exige conscientização, por parte de todos os envolvidos, para que haja sincronia entre os objetivos de aprendizagem propostos e os alcançados e foi, partindo desse pressuposto, que o desenho deste estudo foi delineado.

Observou-se, neste estudo que, em todas as questões avaliativas do problema, as notas atribuídas pelos discentes foram maiores que as dos tutores, com diferença estatisticamente significante em todas as questões.

Na questão 1, ao comparar o grau de facilidade em identificar questões dos problemas dos discentes e tutores, verifica-se que este critério é avaliado com notas maiores pelos discentes embora ambos tenham atribuído conceito de boa identificação.

De modo geral, a nota atribuída a esta questãoreflete o percurso que o discente trilhou, ou seja, partindo do conhecimento prévio para a resolução final do problema. 
Desta forma, pelo fato dos discentes atribuírem notas elevadas nesta questão sugere que o discente alcançou, mesmo que em parte, os objetivos propostos.

Neste caso, o conhecimento adquirido mesmo que não contemple a expectativa do tutor, é avaliado como positivo pelo discente, demonstrado assim uma discrepância entre as notas de discentes e tutores quando se refere aos aspectos de facilidade em identificar as questões trazidas pelo problema.

É importante destacar que os problemas utilizados nos tutoriais são de responsabilidade dos tutores com experiência no assunto a ser tratado. Desta forma, os tutores que elaboram os problemas devem levar em consideração, além de as especificidades da área, alguns aspectos como clareza, associação do assunto específico a ser tratado, articulado à conjuntura atual do Sistema de Saúde no Brasil e Mundial e as possibilidades de se levantar hipóteses relacionadas ao assunto, dentre outros. E o discente, por ainda não ter esta clareza, pode perceber como atingido à identificação das questões, quando na verdade, não o foi requerendo, neste quesito, reformulação das SPs.

Embora na metodologia ativa de ensino ainda se construa um mecanismo de controle dos resultados dos conhecimentos adquiridos pelos discentes, é necessário que se garanta os conhecimentos mínimos exigidos pelo currículo, para isto os objetivos cognitivos são pré-estabelecidos pelos tutores e quando não coincidem com os dos discentes se torna necessária a modificação dos problemas.

Sem dúvida, uma das dificuldades na ABP é a elaboração dos problemas que, ao apresentar falhas em sua estruturação, pode prejudicar o processo de aprendizagem dos discentes, logo no início do levantamento de hipóteses, momento em que o conhecimento prévio vem à tona (ODA; KOISUMI, 2008).

Levantar hipótese requer interpretação ao conteúdo trazido no problema, atenção nas colocações de todos os participantes e, acima de tudo, sensibilidade para tratar do assunto "sem perder o foco". Neste estudo, percebe-se que os discentes avaliam o grau de facilidade de se levantar hipóteses com maiores notas que os tutores. Neste quesito, a diferença significante das notas atribuídas entre discentes e tutores pode ser explicada pelo fato de que os problemas apresentam de forma implícita as hipóteses, o que dificulta, na percepção do tutor, a discussão nas Sessões Tutoriais. O que para o discente é visto de maneira positiva, para o tutor, algumas premissas fundamentais da ABP como a discussão em grupo, a exposição do raciocínio e resolução do problema não foram contempladas totalmente de acordo com os preceitos constituintes do processo de aprendizagem. 
A abordagem de ensino, nesta metodologia, manifesta-se por meio de casos ou situações "simulando cenários reais" que, fragmentado em objetivos, busca envolver o discente na tentativa de resolver os problemas expostos por meio de estratégias na busca por soluções. Nesta perspectiva, o discente deve ser capaz de interpretar os problemas com base em suas experiências e conhecimento prévio e ainda, elencar pontos que possam auxiliar na resolução do problema em questão. $\mathrm{O}$ envolvimento dos discentes na $\mathrm{ABP}$ é parte essencial para a resolução dos objetivos expostos e, consequentemente, no melhor aproveitamento no processo de aprendizagem (WARD; HARTLEY, 2006). Dentro deste contexto, os problemas servem como gatilhos para aprendizagem (WARD; HARTLEY, 2006) e a facilidade em identificar os objetivos alvos do problema contribuem para sua resolução.

$\mathrm{Na}$ avaliação que diz respeito à facilidade em identificar os objetivos dos problemas (questão 3), os discentes avaliaram com notas maiores quando comparado aos tutores. Isto talvez ocorra, pois, alguns problemas trazem assuntos específicos da área, refletindo na dificuldade do uso de conhecimentos prévios e consequentemente dificuldade para levantar hipóteses e traçar objetivos para resolução do problema, que segundo os resultados deste estudo é percebido de forma diferente entre os tutores e os discentes.

A facilidade para resolver os problemas propostos depende do acesso a livros e artigos científicos. Esta etapa exige um senso crítico por parte do aluno e um discernimento de qual referência bibliográfica estudar. Provavelmente por isto, o tutor tenha identificado os resultados desta etapa de forma diferente dos discentes. $\mathrm{O}$ fato dos professores terem atribuído em média a nota 3,04 nos indica que, mesmo em um momento histórico em que muitos artigos e livros são publicados diariamente, os alunos são capazes de escolher bases de dados confiáveis e, mesmo em face de tanta informação, tem conseguido de modo satisfatório resolver os problemas propostos. Além disto, a Aprendizagem baseada em problemas, inspirada na Escola Nova, prepara os alunos a resolverem os problemas que enfrentarão no exercício de sua profissão (CYRINO; TORALLES-PEREIRA, 2004). Aprendem a buscar ativamente seu conhecimento e as respostas para as questões profissionais.

Outra etapa de grande importância nesta metodologia e que possibilita que todos assumam ao mesmo tempo a função de aluno e professor é o momento da discussão. Nesta hora, as acomodações dos conhecimentos prévios e das novas informações cedem espaço para a síntese e aplicação do novo conhecimento. Um conhecimento novo e 
auto-construído. Um grupo de tutorial, portanto, se torna um local de discussão possibilitando a interação humana, em que o aluno aprende a realizar e receber críticas (CYRINO; TORALLES-PEREIRA, 2004). Neste estudo, esta foi a questão em que os tutores atribuíram maiores notas $(3,33)$, o que indica que, os alunos inseridos nesta metodologia têm desenvolvido, dentre outras características essenciais ao exercício profissional, a expressão oral e a facilidade em desenvolver uma discussão consistente e aprofundada.

A avaliação, no que diz respeito à presença de questões biopsicossociais (questão 6), também foi melhor pontuada pelos discentes e este foi o critério que obteve as menores notas, tanto por tutores quanto também pelos discentes. A preocupação de que os profissionais de saúde tenham uma formação articulada com as práticas e políticas de saúde interligada aos movimentos sociais e a real demanda da sociedade existe há muito tempo, pois historicamente a formação destes profissionais, de um modo geral, não os prepara para atuar no campo da promoção à saúde, por exemplo, devido ao enfoque ainda predominantemente biologicista, curativo e médico-centrado (CHIESA et al., 2007). A ABP por seu caráter dinâmico e contextualizado com os movimentos da sociedade deve estar atenta às questões sociais, psíquicas, não descaracterizando a importância do funcionamento biológico dos indivíduos, mas propondo temas de aprendizado que considerem o funcionamento do indivíduo em sociedade e que características sociais e culturais estejam explícitas nas discussões.

Estes resultados indicam a preocupação com a reformulação constante dos problemas, principalmente no que se refere à abordagem biopsicossocial, ponto essencial em uma metodologia ativa de ensino em Saúde.

Repensar a prática e transformá-la é uma das premissas de toda metodologia de ensino em que, tutor e discente, aprendem juntos e reformulam os seus conceitos, de forma ativa durante todo o percurso de construção da aprendizagem.

\section{CONCLUSÃO}

De modo geral, não houve concordância entre as avaliações das SPs entre docentes e discentes, aventando-se a hipótese de que o tutor, por ser mais exigente, considere que o discente apresenta capacidade de produzir mais e, em contrapartida, o discente reconhece os desafios de suas próprias produções, valorizando-as de forma diferente da expectativa docente. De outra forma, ambos os grupos fizeram, em média, uma boa apreciação das SPs adotadas no Ciclo deste estudo. Além disso, outra 
possibilidade é de que as notas possam ser emitidas pelo discente sem que haja uma profunda reflexão sobre as mesmas ou que o pouco conhecimento sobre o assunto os impossibilite de uma análise mais crítica e criteriosa com relação aos objetivos que conseguiram elencar.

Faz-se necessário, portanto, a realização de novos estudos sobre a avaliação das práticas na $\mathrm{ABP}$, a escassez de pesquisas sobre a temática foi percebida durante a construção deste estudo. Compartilhar informações sobre as experiências e práticas na ABP subsidiará a construção de um modelo pedagógico de aprendizagem tido como uma tendência mundial e recentemente adotado pelo Brasil.

\title{
ASSESSMENT OF THE PROBLEM-SITUATION BY TUTORS AND STUDENTS ON A COURSE OF UNDERGRADUATE EXPERIENCED IN ACTIVE METHODOLOGIES
}

\begin{abstract}
: the objective of this text is compare the assessments of students and tutors about the problems used in a Phonoaudiology course structured in active methodologies. The comparison was performed of formative assessment by 30 students and four tutors of Cycle II of Phonoaudiology course at a public university. 36 problem situations were analyzed using scales from zero (poor) to four (excellent), assigned to evaluate problem situations. The results were analyzed statistically (Kappa coefficient and Mann - Whitney, with a significance level of $5 \%$ ). There was no agreement between the evaluations of the problems by students and tutors (Kappa index=0.0036), and that students given higher scores for the issues of problems (mean: 3.7 ) when compared to the tutors (mean: 3.16 ), although all have assigned good facility for the resolution of problem situations. There was no agreement between the evaluations of problem situations between tutors and students.
\end{abstract}

KEYWORDS: Educational assessment. Education. Problem-based learning.

\section{REFERÊNCIAS}

BLOOM, B.; HASTINGS, J. T.; MADAUS, G. F. Manual de avaliação formativa e somativa do aprendizado escolar. São Paulo: Pioneira, 1971.

CHIESA, A. M. et al. A formação de profissionais da saúde: aprendizagem significativa à luz da promoção da saúde. Cogitare Enfermagem, Paraná, v.12, n.2, p.236-240, 2007.

CHUEIRI, M. S. F. Concepções sobre a avaliação escolar. Estudos em Avaliação Educacional, São Paulo, v.19, n.39, p.49-64, 2008. 
CYRINO, E. G.; TORALLES-PEREIRA, M. L. Trabalhando com estratégias de ensino-aprendizado por descoberta na área da saúde: a problematização e a aprendizagem baseada em problemas. Caderno de Saúde Pública, Rio de Janeiro, v.20, n.3, p.780-788, 2004.

DOLMANS, D. H. J. M. et al. Problem-based learning: future challenges for educational practice and research. Medical Education, Maastricht, v.39, p.732-741, 2005.

FERNANDES, D. Para uma teoria da avaliação no domínio das aprendizagens. Estudos em Avaliação Educacional, São Paulo, v.19, n.41, p.347-372, 2008.

FLEISS, J. L. Statistical methods for rates and proportions. New York: John Wiley and Sons, 1981.

FREIRE, P. Pedagogia da autonomia: saberes necessários à prática educativa. 33.ed. São Paulo: Paz e Terra, 2006.

GARCIA MADRUGA, J. A. Aprendizagem pela descoberta frente à aprendizagem pela recepção: a teoria da aprendizagem verbal significativa. In: COLL, C.; PALÁCIOS, J.; MARCHESI, A. (Org.). Desenvolvimento psicológico e educação. Porto Alegre: ARTMED, 1996. p.68-78.

GOMES, M. P. C. et al. The use of active learning methodologies in graduate courses in health and social sciences - students's evaluation. Ciência \& Educação, Bauru, v.16, n.1, p.181-198, 2010.

HITCHCOCK, M. A.; ANDERSON, A. S. Dealing with dysfunctional tutorial groups. Teaching Learning Medicine, Philadelphia, v.9, p.19-24, 1997.

$\mathrm{KOH}, \mathrm{G}$. C. et al. The effects of problem-based learning during medical school on physician competency: a systematic review. CMAJ, Ottawa, v.178, n.1, p.34-41, 2008.

KOLKHORST, B. B.; YAZEDJIAN, A. Implementing small-group activities in large lecture classes. College Teaching, Washington, v.55, n.4, p.164-169, 2007.

LIMA, G. Z.; LINHARES, R. E. C. Escrever bons problemas. Revista Brasileira de Educação Médica, Rio de Janeiro, v.32, n.2, p.197-201, 2008.

MARIN, M. J. S. et al. Pós-graduação multiprofissional em saúde: resultados de experiências utilizando metodologias ativas. Interface, Botucatu, v.14, n.33, p.331-344, 2010.

ODA, Y.; KOISUMI, S. Status of medical education reforma t Saga Medical School 5 years after introducing PBL. Kaohsiung Journal of Medical Sciences, Singapore, v.24, n.3, p.S46-53, 2008.

SCHMIDT, H. A base lógica de aprendizagem em resolução de problemas. In: ENGEL, C.; MAJOOR, G.; VLUGGEN, P. Educação de profissionais de saúde orientada 
para a comunidade: uma seleção de publicações da Network. Maastricht: Network Publications, 1999. p.83-90.

SILVA, R. H. A.; SCAPIN, L. T. Utilização da avaliação formativa para a implementação da problematização como método ativo de ensino-aprendizagem. Estudos em avaliação Educacional, São Paulo, v.22, n.50, p.537-552, 2011.

ZANOTTO, M. A. C.; DE ROSE, T. M. S. Problematizar a própria realidade: análise de uma experiência de formação contínua. Educação e Pesquisa, São Paulo, v.29, n.1, p.45-54, 2003.

WARD, K.; HARTLEY, J. Using a virtual learning environment to address one problem with problem based Learning. Nurse Education in practice, Edinburgh, v.6, n.4, p.185-191, 2006. 